\title{
REVIEW
}

\section{Exploring the pathophysiology behind the more common genetic and acquired lipodystrophies}

\begin{abstract}
Tom Nolis
Lipodystrophies are an immense group of genetic or acquired metabolic disorders that are characterized by varying degrees of body fat loss and in some instances localized accumulation of subcutaneous fat. Lipodystrophies are often tightly linked with profound metabolic complications; this strong bond emphasizes and reinforces the significance of adipose tissue as a dynamic endocrine organ. The extent of fat loss determines the severity of associated metabolic complications such as diabetes mellitus, hypertriglyceridemia and hepatic steatosis. The lipodystrophies can be divided into generalized, partial or local, depending on the degree and locality of the observable fat loss; moreover, the generalized and partial divisions can be partitioned further into inherited or acquired forms. The major genetic factors in the generalized forms of the lipodystrophies, particularly Congenital generalized lipodystrophy (CGL)-Berardinelli-Seip syndrome, are the AGPAT2, BSCL2, caveolin 1 (CAV1) and polymerase-I-andtranscriptrelease factor (PTRF) genes. In the acquired forms, genes such as LMNA, PPARG, CIDEC (cell-death-inducing DNA fragmentation factor a-like effector $\mathrm{c}$ ) and PLIN1 are heavily involved in familial partial lipodystrophy (FPLD) type 2 (also known as the Dunnigan-Variety) and WRN along with RECQL5 in Werner Syndrome (WS). Autoimmune causes are particularly noted in acquired partial lipodystrophy (APL)-Barraquer-Simons syndrome and in AGL-Lawrence syndrome; panniculitis has been shown to have a substantial role in the former as well as in other forms of localized lipodystrophies. Patients with human immunodeficiency virus (HIV) exposed to protease inhibitors, nucleoside reverse transcriptase inhibitors (NRTIs) (for example, zidovudine and stavudine) or non-nucleoside reverse transcriptase inhibitors (NNRTIs) (for example, efavirenz) while undergoing Highly Active Antiretroviral Therapy (HAART) have led to the current most-prevalent form of the lipodystrophies: lipodystrophy in HIV-infected patients (LD-HIV) and HAART-associated lipodystrophy syndrome (HALS).
\end{abstract}

Journal of Human Genetics (2014) 59, 16-23; doi:10.1038/jhg.2013.107; published online 24 October 2013

Keywords: genetics; HIV; lipodystrophy; pathophysiology

\section{INTRODUCTION}

Lipodystrophies are a vast group of metabolic disorders characterized by varying degrees of body fat loss. ${ }^{1}$ Many of these lipodystrophies are outlined by either a redistribution of fat or an abnormal localized accumulation of fat, and the perilousness of these disorders is strongly correlated with the degree of fat loss observed. ${ }^{2}$ The inherent nature of the metabolic abnormalities in these disorders yields an array of complications including a combination of diabetes mellitus, insulin resistance and acanthosis nigricans; hypertriglyceridemia; and hepatic steatosis. Other common impediments that have been noted include hypertension, polycystic ovarian disease and proteinuric kidney disease. ${ }^{1,2}$

The lipodystrophies can be divided into generalized, partial or local, depending on the degree and locality of the observable fat loss; moreover, the generalized and partial divisions can be partitioned further into inherited or acquired forms. Local forms of the disorder tend to confer no metabolic impediments, which differ greatly from the generalized and partial divisions that tend to produce a complex assortment and spectrum of metabolic complications.
With the advent and implementation of Highly Active Antiretroviral Therapy (HAART) for human immunodeficiency virus (HIV)infected patients, nearly half of the patients receiving HAART are acquiring a form of HIV-associated lipodystrophy syndrome (HALS), which has recently surpassed all other forms of lipodystrophies to become the most-prevalent form and also the form with the highest incidence among all the currently known lipodystrophies. ${ }^{3-5}$

This paper purposes to evaluate and describe the classification of the more common lipodystrophic syndromes and the underlying mechanisms responsible for the affiliated metabolic abnormalities observed.

Overview of adipose tissue and normal adipocyte maturation Adipose tissue is an intricate, highly active metabolic and endocrine organ. ${ }^{6}$ The tissue is amassed mainly of adipocytes; however, a delicate network of connective tissue, nerve cells, stromovascular cells and immune cells adds to the functionality of this essential organ. Adipose tissue is extraordinarily responsive to hormonal signals and to the demands of the CNS and also has a major role 
in secreting sex steroids and glucocorticoids. Various metabolic hormones, mainly insulin and steroids, induce transcription factors to prompt the pre-adipocyte to begin to differentiate into a standard adipocyte. Once feeding or elevated substrate is available for the cell to thrive, lipid droplets begin to form within the adipocyte, which differentiate the adipocyte's level of maturity. ${ }^{7}$ Lipid droplets are small organelles that store triglycerides intracellularly, and they form as the vesicles within the endoplasmic reticulum fuse and accumulate. As these droplets grow in size and number, the adipocyte subsequently increases in bulk, yielding a fully formed mature adipocyte-this process is essentially reversed in periods of fasting or starvation. ${ }^{1,7}$ Normal adipose tissue functions to assure protection against lipo- and glucotoxicity. This is accomplished by adipocyte differentiation from precursor cells and the maturation to triglyceride-saturated adipocytes. ${ }^{8}$

At the heart of the essentiality and functionality of adipose tissue lies the adipocyte. The adipocyte, similar to other cell types, undergoes a period of development and a progressive maturation or differentiation stage. Adipogenesis can be described in two phases. The first phase, determination, begins with the commitment of a pluripotent stem cell to the adipocyte lineage. These stem cells can give rise to early muscle or bone cells as well as the young fat cells. The fate of determination results in the conversion of the stem cell to a pre-adipocyte, which, although it cannot be distinguished morphologically from its precursor cell, has lost its potential to differentiate into other cell types. The second phase, terminal differentiation, incorporates pre-adipocyte maturation (Figure 1). ${ }^{9}$

Signals from activators and repressors of adipogenesis are integrated in the nucleus by transcription factors that directly or indirectly regulate the expression of peroxisome proliferator-activated receptor gamma (PPARG) and other factors such as CCAATenhancer-binding protein alpha (C/EBP alpha). ${ }^{9} P P A R G$, a member of the nuclear-receptor superfamily, is considered the master regulator of adipogenesis as no factor has been discovered that promotes adipogenesis in the absence of PPARG. ${ }^{10} P P A R G$ is not only crucial for adipogenesis, it is also required for the maintenance of the differentiated state. Viral introduction of a dominant-negative PPARG into mature 3T3-L1 adipocytes causes dedifferentiation, resulting in lipid loss and an overall decrease in expression. ${ }^{9}$ Additionally, in vivo experiments involving the knockout of $P P A R G$ in differentiated adipocytes leads to adipocyte death followed by a proliferation of new adipocytes. ${ }^{9,11}$ The transcription factor cyclic AMP response element-binding protein functions early in adipogenesis to regulate the expression of $C / E B P$ alpha and PPARG, whereas GATA2/3 and $S M A D 3$ closely interact with $C / E B P$ alpha to inhibit its transcriptional activity on the PPARG2 promoter. $^{9,11}$

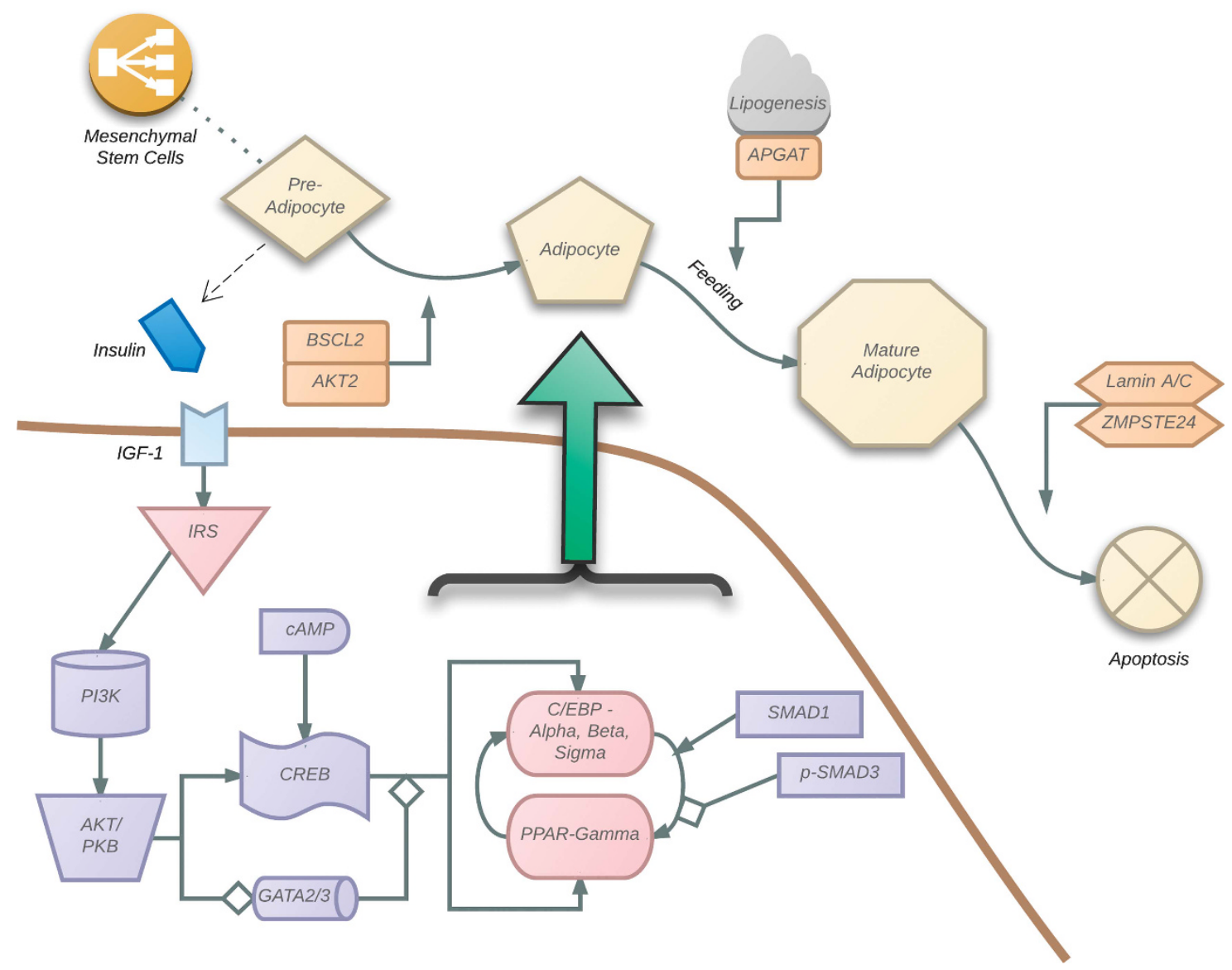

Figure 1 Adipocyte differentiation and regulation. Pathways are involved in the development, differentiation and death of adipocytes, along with signals from activators and repressors of adipogenesis that amalgamated in the nucleus. The pluripotent mesenchymal stem cells can go on to form pre-adipocytes. In response to hormones such as insulin, successions of changes are initiated in pre-adipocytes that directly or indirectly regulate the expression of peroxisome proliferator-activated receptor- $\gamma$ (PPAR $\gamma$ ) and C/EBP Alpha, Beta and Sigma. These changes and influences lead to the differentiation to mature adipocytes and eventually cell death. Solid arrowhead-positive effect; Hollow diamond arrowhead negative effect. IGF 1, insulin growth factor-1; IRS, insulin receptor substrate; PI3K, phosphatidylinositol-3 kinase. 
Insulin is heavily involved in promoting differentiation by functioning through at least four different mechanisms to promote adipocyte differentiation. ${ }^{9}$ In the early stages of adipogenesis, insulin functions predominantly through insulin growth factor-1 (IGF1) receptor signaling, as pre-adipocytes express many more receptors for IGF1 than for insulin; furthermore, this ratio shifts as differentiation progresses. ${ }^{9}$

Downstream components of the insulin/IGF1 signaling cascade are decisively important for adipogenesis. Inhibition of phosphatidylinositol-3 kinase and AKT1/protein kinase B (PKB) or AKT2/PKB stifles adipogenesis. Mice that lack both $A K T 1$ and $A K T 2$ will undoubtedly be lipoatrophic. The relevance of this pathway in humans is buttressed by the identification of families with lipoatrophic diabetes that carry AKT2 mutations. ${ }^{9,11}$

Lamins A and C, encoded by the LMNA gene, are nuclear proteins expressed in all post-mitotic cells. Along with B-type lamins, these proteins form a meshwork below the inner nuclear membrane, the lamina, which is linked with the cytoskeleton. LMNA mutations are thought to induce structural modifications, thus affecting their polymerization into the nuclear lamina leading to the accumulation of cytotoxic immature proteins. Defects such as these would lead to a mechanical weakness of the nuclear lamina, and many of these mutations are accountable for several of the laminopathies. ${ }^{11}$

Adipocytes provide a benign place to store lipids; when these cells are absent, as is the case in the lipodystrophies, lipids will accumulate in the muscle, liver and other areas of the body. This accumulation ultimately causes significant metabolic instability, including insulin resistance, hepatosteatosis or cirrhosis. ${ }^{8-11}$

\section{Generalized lipodystrophies}

Generalized lipodystrophies correspond with fat loss affecting the whole body rather than a single region. There are both congenital and acquired forms. The most common types are Berardinelli-Seip syndrome and Lawrence syndrome.

Congenital generalized lipodystrophy (CGL), Berardinelli-Seip Syndrome. CGL-Berardinelli-Seip syndrome is an exceptionally rare autosomal recessive disorder-roughly 300 cases reported-in which patients are virtually devoid of body fat (Table 1). Most cases reported have ascended from consanguineous families in Brazil, Lebanon and Scandinavia. ${ }^{12-15}$ There are two forms of this syndrome, with each form implicating a distinct set of genes.

The first one of these forms (CGL1) involves a mutation on the fourth band, of the third region, which resides on the long arm of chromosome nine-9q34-specifically involving the 1-acylglycerol-3phosphate-O-acyltransferase 2 (AGPAT2) gene. ${ }^{16,17}$ AGPAT2 is an enzyme that has a significant role in lipogenesis by catalyzing the formation of phosphatidic acid-an intracellular signaling molecule. ${ }^{17,18}$ Phosphatidic acid has an essential part in developing young adipocytes into their mature forms. ${ }^{17} \mathrm{~A}$ recent study revealed that mutations in AGPAT2 cause cyclic phosphatidic acid to decrease and that the reduced generation of phosphatidic acid could be leading to reduced PIP3 levels, impaired activation of $A K T$ and ultimately an increase in apoptosis. ${ }^{18}$ AGPAT2 is decidedly expressed in adipose tissue that is metabolically important (for example, bone marrow, subcutaneous and intermuscular) and its insufficiency may cause lipodystrophy by restricting triglyceride or phospholipid biosynthesis within the tissue. ${ }^{19,20}$

The second of these forms (CGL2) involves a mutation on the thirteenth band, of the thirteenth region, which resides on the long arm of chromosome eleven-11q1313 - specifically involving the Berardinelli-Seip Congenital Lipodystrophy 2 (BSCL2) gene. ${ }^{19}$ The BSCL2-encoded protein, also known as seipin, is a homooligomeric integral membrane protein, within the endoplasmic reticulum, that concentrates at junctions with cytoplasmic lipid droplets. ${ }^{21,22}$ Seipin regulates lipid homeostasis by limiting lipogenesis and lipid droplet accumulation in non-adipocytes, whereas promoting adipogenesis in periods of excess energy storage. ${ }^{23}$ If seipin functions were altered, adipocyte maturation would be severely impeded. ${ }^{21,22}$ Patients with BSCL2 mutations lack metabolically important adipose tissue, similar to patients with CGL1, as well as the mechanically important adipose tissue (for example, on the palms and soles). ${ }^{20}$ Owing to the compound nature of losing both metabolically and mechanically active adipose tissues, CGL2 yields the most severe form of CGL. ${ }^{20}$

These candidate genes have led to two other important genetic mutation detections: caveolin $1(C A V 1)$ and polymerase-I-andtranscriptrelease factor $(P T R F) .{ }^{24,25}$ The caveolins are crucial

Table 1 Inherited Lypodystrophies-Generalized Fat Loss

\begin{tabular}{|c|c|c|c|c|}
\hline Type & Key genes & Gene function & Clinical features & Pathophysiology/molecular basis \\
\hline \multirow[t]{4}{*}{$\begin{array}{l}\text { Berardinelli-Seip } \\
\text { Syndrome }\end{array}$} & AGPAT2 & $\begin{array}{l}\text { AGPAT2 catalyzes formation of } \\
\text { phosphatidic acid }\end{array}$ & $\begin{array}{l}\text { Lack of metabolically active adipose } \\
\text { tissue from birth }\end{array}$ & $\begin{array}{l}\text { Mutations in AGPAT2 } \\
\text { Decrease phosphatidic acid } \\
\text { Reduced PIP3 levels } \\
\text { Impaired activation of AKT } \\
\text { Increase in apoptosis }\end{array}$ \\
\hline & BSCL2 & $\begin{array}{l}\text { BSCL2, also known as seipin, regulates } \\
\text { lipid homeostasis } \\
\text { Limits lipogenesis, lipid droplet } \\
\text { accumulation in non-adipocytes } \\
\text { Promotes adipogenesis in periods of } \\
\text { excess energy }\end{array}$ & $\begin{array}{l}\text { Lack of both metabolically active and } \\
\text { mechanical adipose tissue from birth } \\
\text { Mental retardation } \\
\text { Cardiomyopathy }\end{array}$ & $\begin{array}{l}\text { Mutations in BSCL2 } \\
\text { Hinder adipogenesis }\end{array}$ \\
\hline & CAV1 & $\begin{array}{l}\text { Caveolin } 1 \text { binds and transports fatty } \\
\text { acids to lipid droplets }\end{array}$ & $\begin{array}{l}\text { Lipoatrophic } \\
\text { Short stature }\end{array}$ & $\begin{array}{l}\text { Inability to augment insulin signaling } \\
\text { and modulate GLUT4 function }\end{array}$ \\
\hline & PTRF & $\begin{array}{l}\text { Creates caveolae and regulates } \\
\text { expression of caveolins } 1 \text { and } 3\end{array}$ & $\begin{array}{l}\text { Lipoatrophic } \\
\text { Pyloricstenosis } \\
\text { Cardiomyopathy }\end{array}$ & $\begin{array}{l}\text { Loss-of-function of Caveolin } 1 \text { and } 3 \\
\text { Inability to augment insulin signaling } \\
\text { and modulate GLUT4 function }\end{array}$ \\
\hline
\end{tabular}

Abbreviation: PTRF, polymerase-I-and-transcriptrelease factor 
elements of the caveolae-invaginations of the plasma membranewhich are involved in signal transduction and transport of cellular material. ${ }^{26}$ Patients afflicted with PTRF mutations suffer from pyloric stenosis, congenital myopathy, muscular dystrophy, percussioninduced myoedema and cardiac rhythm disturbances. ${ }^{25-28}$

Acquired generalized lipodystrophy (AGL), Lawrence Syndrome. The pathogenesis of fat loss in patients with AGL is highly variable, and the exact nature of this syndrome remains largely unknown. Clinically, most of the AGL patients have generalized loss of fat but a minority present with sparring of intra-abdominal and bone marrow fat (Table 2). ${ }^{29}$

Roughly one quarter of AGL cases are triggered by panniculitisinflammation of the subcutaneous fat, especially of the abdominal wall-that progresses from local fat loss to generalized or total. An additional quarter is autoimmune in origin, stemming from conditions such as rheumatoid arthritis, systemic lupus erythematosus, Sjogren syndrome and juvenile dermatomyositis. ${ }^{30}$ The remainder is essentially idiopathic in origin with a variety of underlying, and less clear, mechanisms at play. ${ }^{31}$

Interestingly, many patients with AGL have been found to suffer from chronic hepatitis with additional autoimmune features and low serum complement four levels. ${ }^{32}$

\section{Partial lipodystrophies}

Partial lipodystrophies correspond with fat loss affecting areas of the body but spare the body as a whole. There are inherited, acquired and induced forms. The most common types are Barraquer-Simons syndrome, familial partial lipodystrophy, adult progeria Werner syndrome (WS), HALS and localized lipodystrophy.

Acquired partial lipodystrophy (APL), Barraquer-Simons syndrome. APL-Barraquer-Simons syndrome is another exceptionally rare disorder, with $\sim 250$ cases reported (Table 2 )..$^{33}$ A distinctive pattern of fat loss is observed in patients afflicted with Barraquer-Simons syndrome: fat loss is progressively lost in the superior half of the body while sparring the lower limbs. Of note, fat deposition is not only sparred in the lower extremities but it can also be augmented, and at times excessive in these areas, particularly in the hips and thighs. ${ }^{34}$ Approximately $20 \%$ of these patients may, at some point, develop membranoproliferative glomerulonephritis, and some may progress to adopt drusen - small accumulations of hyaline bodies underneath the retina. ${ }^{31}$ However, despite this peculiar fat loss and deposition pattern, metabolic complications, apart from hepatomegaly, are usually nonexistent. ${ }^{33,34}$

The precise pathogenesis of APL-Barraquer-Simons syndrome remains a mystery; however, autoimmune and genetic theories have surfaced in hopes of explaining this rare condition. Leading autoimmune theories favor complement pathway alterations. Mature adipocyte destruction seen in these patients is strongly linked to low serum levels of complement 3 and the presence of the complement 3-nephritic factor, which accounts for the relatively high incidence of membranoproliferative glomerulonephritis. ${ }^{33}$ C3-nephritic factor also induces the lysis, or cleavage, of adipocytes that express factor $\mathrm{D}$ - a serine protease enzyme-and the overt expression of factor D by numerous tissues in the body produces the characteristic fat loss and accumulation pattern observed in this

Table 2 Acquired lypodystrophies

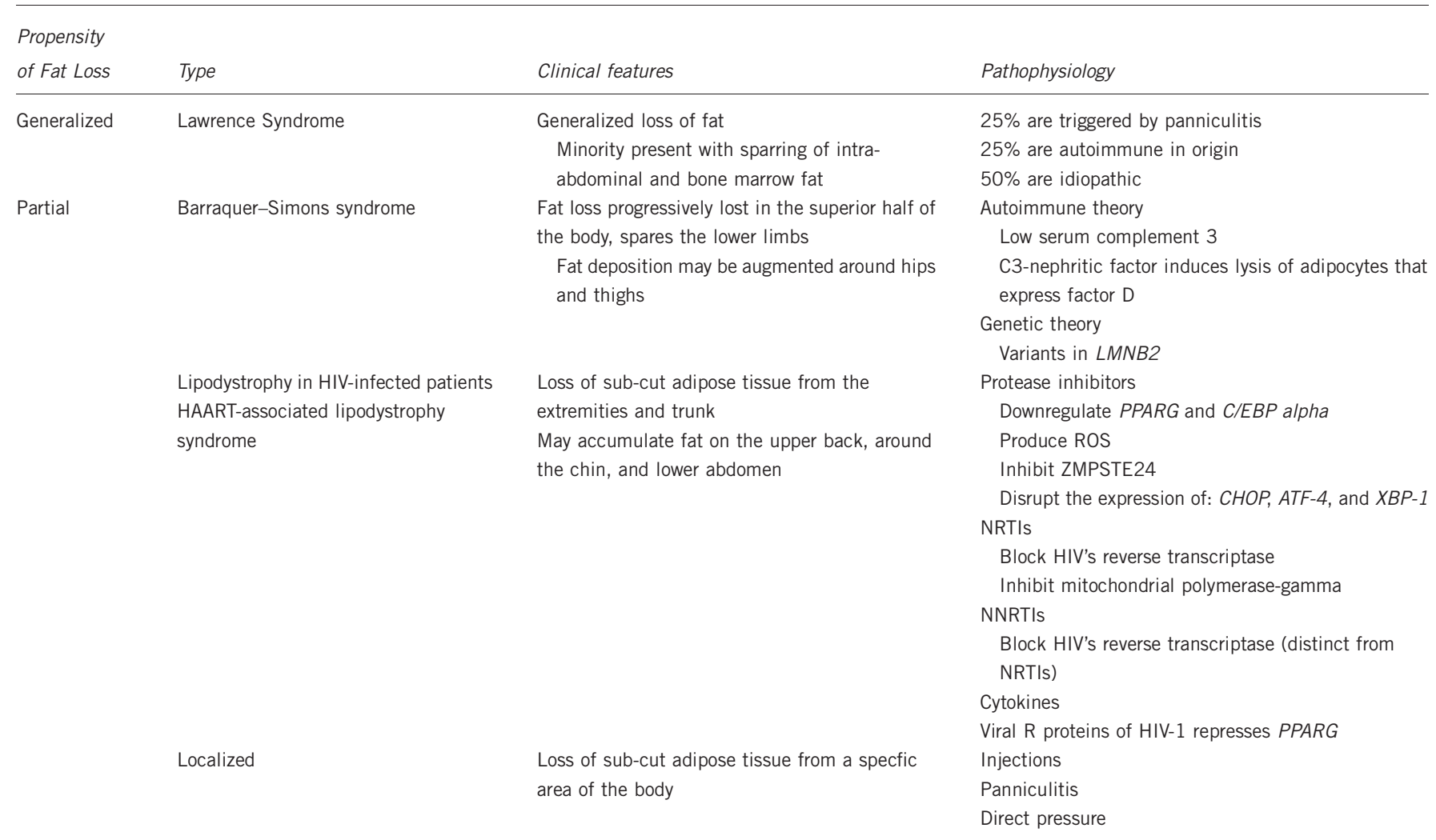

Abbreviations: C/EBP, CCAAT-enhancer-binding protein alpha; HAART, Highly Active Antiretroviral Therapy; PPAR, peroxisome proliferator-activated receptor gamma; ROS, reactive oxygen species. 
syndrome. ${ }^{33-36}$ The leading genetic theory proposes variants in the $L M N B 2$ gene, responsible for the nuclear lamin B-type. However, the fat loss observed in patients afflicted with LMNB2 gene mutations progressed more inferiorly than has been typically detected in APL-Barraquer-Simons syndrome patients. ${ }^{37}$

Inherited partial lipodystrophy, familial partial lipodystrophy (FPLD). Clinically, FPLD is depicted by fat loss from the limbs and the extremities, the abdomen and the chest; moreover, some patients may accumulate fat in a Cushingoid manner (Table 3). ${ }^{38}$ The timing of fat loss is variable as it can occur at virtually any stage of growth and development, from childhood to well within adulthood. ${ }^{39-41}$ The mode of inheritance can vary considerably as well, ranging from autosomal dominant, autosomal recessive and X-linked traits. ${ }^{21}$ Similar to many other lipodystrophies, FPLD is an exceptionally rare condition. The most-prevalent form, the autosomal dominant type 2, the first described familial partial lipoodystrophy, more formally FPLD1 (eponymously coined as Dunnigan-Variety or Dunnigan's Syndrome) holds a prevalence of only 1 in 15 million persons - with only $\sim 300$ cases in empirical literature. ${ }^{38}$ Patients with FPLD2 experience a multitude of metabolic complications including hyperlipidemia, hypertriglyceridemia and diabetes. ${ }^{42}$ Females appear to be more afflicted than their male counterparts, and many women, up to $25 \%$, experience reproductive difficulties including, polycystic ovarian syndrome, infertility and gestational diabetes. ${ }^{21,43}$ Some patients will evolve varying degrees of myopathy, cardiomyopathy and other conduction system abnormalities. ${ }^{44,45}$

FPLD2 involves a mutation on the long arm of chromosome one, 1q21-22, specifically involving the Lamin A/C or LMNA gene-a fundamental constituent of the nuclear lamina. ${ }^{46-48}$ The disruption of lamins A and C is believed to weaken the integrity and framework of the nuclear envelope, which would profoundly deteriorate the structure of the adipocyte nucleus, ultimately leading to premature cell death. ${ }^{49,50}$
After identification of the LMNA gene, a candidate approach revealed the following four genes of interest: v-AKT murine thymoma oncogene homolog 2 (AKT2), PPARG, cell-death-inducing DNA fragmentation factor a-like effector $\mathrm{c}(C I D E C)$ and perilipin 1 (PLIN1). ${ }^{48,51-54}$ Mutations in PPARG have been classified into the third type of familial partial lipodystrophy (FPLD3); ${ }^{48}$ defects in this gene along with AKT2 are likely to hinder or alter adipocyte maturation. ${ }^{55}$ Patients with mutations in PLIN1 tend to develop micro-adipocytes that are susceptible to macrophage invasion, which eventually yield fibrotic changes within the adipose network. ${ }^{56}$

Adult progeria, WS. WS is an autosomal recessive syndrome resulting in premature aging (Table 3). Its most prominent and notable features typically occur after adolescence and include scleroderma-like skin changes, 'bird-like' facies, bilateral cataracts, short stature, high incidence of neoplastic changes and premature graying of scalp hair. ${ }^{57}$

The nature of this lipodystrophy is complex and involves the biallelic inactivation of mutations in the WS (WRN) protein, which encodes a RecQ DNA helicase/exonuclease that is involved in DNA replication and repair and is highly implicated in the maintenance of genome stability. ${ }^{57}$ The gene is located on the $8 \mathrm{p} 11-12$ locus and it encodes the 1432 amino-acid WRN protein that is homologous to the RecQ subfamily helicases. ${ }^{58}$ On the basis of the indigenous Japanese, the WRN loss-of-function mutation heterozygote rate nears 6 per 1000; it is speculated that $\sim 1200$ heterozygotes reside in Hawaii. ${ }^{59}$

WRN has a critical role in responding to replication fork stress and significantly contributes to the recovery of stalled replication forks, and recent literature maintains that WRN accomplishes this task by remaining intimate with the replication checkpoint. ${ }^{57}$ The replication checkpoint response, which involves both the ATR and ATM kinase, is allocated to the maintenance of fork integrity as well as to the reestablishment of fork progression. ${ }^{57}$

Table 3 Inherited lypodystrophies—partial fat loss

\begin{tabular}{|c|c|c|c|c|}
\hline Type & Key genes & Gene function & Clinical features & Pathophysiology/molecular basis \\
\hline \multirow[t]{4}{*}{$\begin{array}{l}\text { Familial partial } \\
\text { lipodystrophy }\end{array}$} & LMNA (FPLD2) & $\begin{array}{l}\text { Lamins } \mathrm{A} \text { and } \mathrm{C} \text { are nuclear lamina } \\
\text { proteins linked with the cytoskeleton }\end{array}$ & $\begin{array}{l}\text { Loss of sub-cut adipose tissue from } \\
\text { the extremities and trunk }\end{array}$ & $\begin{array}{l}\text { Affect polymerization into the } \\
\text { nuclear lamina } \\
\text { Accumulation of cytotoxic imma- } \\
\text { ture proteins } \\
\text { Premature apoptosis of } \\
\text { adipocytes }\end{array}$ \\
\hline & PPARG (FPLD3) & $\begin{array}{l}\text { PPARG is crucial for adipogenesis and for } \\
\text { maintenance of the differentiation phase }\end{array}$ & $\begin{array}{l}\text { Loss of sub-cut adipose tissue from } \\
\text { the extremities }\end{array}$ & $\begin{array}{l}\text { PPARG mutations } \\
\text { Inhibits adipocyte differentiation }\end{array}$ \\
\hline & AKT2 (FPLD4) & $\begin{array}{l}\text { AKT2, also known as protein kinase B } \\
\text { Involved in adipocyte differentiation } \\
\text { Downstream insulin receptor signaling }\end{array}$ & $\begin{array}{l}\text { Loss of sub-cut adipose tissue from } \\
\text { the extremities }\end{array}$ & $\begin{array}{l}\text { Mutations in } A K T 2 / P K B \\
\text { Throttles adipogenesis }\end{array}$ \\
\hline & PLIN1 (FPLD5) & $\begin{array}{l}\text { Perilipin } 1 \text { is an essential component for } \\
\text { lipid storage }\end{array}$ & $\begin{array}{l}\text { Loss of sub-cut adipose tissue from } \\
\text { the extremities } \\
\text { Fibrotic adipose tissue }\end{array}$ & $\begin{array}{l}\text { Mutations in PLIN1 } \\
\text { Develop micro-adipocytes sus- } \\
\text { ceptible to macrophage invasion } \\
\text { Yields fibrotic changes within the } \\
\text { adipose network }\end{array}$ \\
\hline Werner's syndrome & WRN & $\begin{array}{l}\text { Encodes a RecQ DNA helicase/exonu- } \\
\text { clease that is involved in DNA replication } \\
\text { and repair }\end{array}$ & $\begin{array}{l}\text { Scleroderma-like skin changes } \\
\text { 'Bird-like' facies } \\
\text { Bilateral cataracts } \\
\text { Short stature } \\
\text { Neoplastic changes } \\
\text { Premature graying of scalp hair }\end{array}$ & $\begin{array}{l}\text { Loss of both RECQL5 and WRN } \\
\text { Compromises DNA replication, } \\
\text { leading to genomic instability } \\
\text { Cell apoptosis }\end{array}$ \\
\hline
\end{tabular}

Abbreviations: FPLD, familial partial lipodystrophy; PPAR, peroxisome proliferator-activated receptor gamma. 
RECQL5 interacts both physically and functionally with WRN, and it perturbs at laser-induced DNA double-stranded breaks in the absence of WRN. RECQL5 cooperates with WRN on synthetic stalled replication fork-like structures and stimulates its helicase activity on DNA fork duplexes. Both RECQL5 and WRN relocalize from the nucleolus into the nucleus after replicative stress and are closely linked during the S phase. Loss of both RECQL5 and WRN profoundly compromises DNA replication, leading to genomic instability and ultimately cell death. ${ }^{60}$

Lipodystrophy in HIV-infected patients (LD-HIV), HALS. LD-HIV may appear in patients receiving HAART with protease-inhibiting agents, and thymidine analogs, after 2 years of therapy (Table 2). ${ }^{5}$ The pattern of fat loss occurs on both upper and lower limbs as well as in the face. Patients may accumulate fat on the upper back, around the chin and around the lower abdomen. ${ }^{61,62}$ Distressingly, the fat loss progressively compounds with ongoing HAART therapy and becomes irreversible despite cessation of the protease inhibitor. Some patients may also develop hypertriglyceridemia and diabetes. ${ }^{63}$

Protease inhibitors downregulate PPAR-gamma and C/EBP alpha, the key adipogenic transcription factors, which, when rendered inactive or ineffective, would severely disrupt lipogenesis and adipocyte maturation. ${ }^{64}$ Protease inhibitors also spawn a considerable sum of reactive oxygen species, in turn encouraging the production of cytokines, leading to macrophage recruitment, inhibition of glucosetransport-4 (GLUT-4)-mediated glucose transport, deficiency in insulin signaling and the subsidization of the imperative leptin and adiponectin hormones. ${ }^{3,65-69}$ Protease inhibitors may also act by inhibiting ZMPSTE24, the metallopeptidase that removes the terminal 15 amino acids in the fourth processing step of prelamin A, resulting in the accumulation of the toxic farnesylated prelamin A. ${ }^{70}$ A recent study revealed specific data on lipoatrophy by evaluating the changes induced in the SW872 pre-adipocytic human cell line by exposure to various protease inhibitors: amprenavir, ritonavir or atazanavir. Results showed that ritonavir caused massive apoptosis, and atazanavir induced both apoptosis and autophagy, at high and low doses, respectively. ${ }^{71}$ Atazanavir-treated cells displayed the formation of autophagosomes that enclosed the mitochondria. ${ }^{71}$ It was striking to note that even at low doses, atazanavir promoted mitochondrial superoxide generation, whereas at high doses, it induced mitochondrial membrane depolarization. ${ }^{71}$ Additional literature has revealed that protease inhibitors differentially activate endoplasmic reticulum-stress pathways via the depletion of endoplasmic reticulum calcium in adipocytes. ${ }^{72}$ Protease inhibitors also disrupt the expression of the key regulatory genes- $\mathrm{CHOP}$, ATF-4 and XBP-1 - thereby altering lipid metabolism and the autophagy flux, which are both vital for the appropriate differentiation and maturation of pre-adipocytes to mature adipocytes. ${ }^{72}$

The exact etiology of LD-HIV from HALS remains elusive; however, additional theories regarding the implications of the preparations used in HAART have been emerging. Nucleoside reverse transcriptase inhibitors (NRTIs) (for example, zidovudine and stavudine), implemented in HAART, are instigated in therapy to actively block HIV's reverse transcriptase's enzymatic function, which, rather effectively, prevents HIV from multiplying by impeding synthesis of double-stranded viral DNA. NRTIs may contribute to LD-HIV by inhibiting mitochondrial polymerase-gamma, effectively evoking mitochondrial toxicity. ${ }^{73-76}$

The influence of non-nucleoside reverse transcriptase inhibitors (NNRTIs) on precipitating lipodystrophy, and other metabolic changes, remains obscure. NNRTIs aim to block reverse transcriptase activity by binding at a different site on the enzyme than their NRTI counterparts. NNRTIs are essentially classified as non-competitive inhibitors of reverse transcriptase by inhibiting the efficacy of various protein domains of reverse transcriptase, thereby hindering the process of viral DNA synthesis. The NNRTI, efavirenz, when combined with either stavudine or zidovudine, yielded greater fat loss than the protease inhibitor lopinavir/ $\mathrm{r}$ when combined with either NRTI. ${ }^{77}$ Furthermore, efavirenz may hamper the accumulation of lipids in pre-adipocytes and mature adipocytes. ${ }^{78,79}$ Despite the substantiation of literature on efavirenz, the evidence regarding the overall impact of NNRTIs on the lipoatrophy in LD-HIV patients refrains from being compelling. ${ }^{77}$

Suggestions of other factors affecting metabolic and fat distribution complications have also emerged. Genetic contributions may have a role in susceptible patients receiving HAART. A missense mutation in the resistin gene has been correlated with limb fat loss, hyperlipidemia and insulin resistance when combined with HAART. ${ }^{80}$ Inflammatory factors appear to compromise the metabolic scaffolding in patients receiving HAART. $^{81}$ GLUT- 4 and insulin receptor substrate- 1 activity are both downregulated by tumor necrosis factor-alpha, a major cytokine that stimulates the acute phase reaction and the regulation of immune cells. ${ }^{3}$ Chronic elevation of IL-6, as observed in chronic inflammatory states, promotes gluconeogenesis and triglyceride secretion, altering insulin production and resistance. ${ }^{3}$ Levels of pro-inflammatory cytokines as well as other cytokines such as tumor necrosis factor-alpha, integrin alpha-M, CD68, monocyte chemoattractant protein-1, a disintegrin and metalloproteinase domain 8 and epidermal growth factor-like module containing mucin-like hormone receptor-like-1 have been shown to elevate in HALS patients. ${ }^{82}$ The encouragement of lipolysis observed in drug-induced lipoatrophy boosts the formation of free fatty acids in the serum. ${ }^{83}$ The excess of free fatty acids both intracellularly and in the viscera has been shown to enforce a state of toxicity to the lipid tissue. ${ }^{84}$ This lipotoxic environment appears to intensify the metabolic disturbances observed, particularly dyslipidemia, hyperlipidemia and insulin resistance. ${ }^{74}$ Lastly, the virus itself may have a direct impact on fat distribution. The viral $\mathrm{R}$ proteins of HIV-1 have been shown to act as a repressor of PPAR-gamma-mediated gene transcription; in much the same way, protease inhibitors influence PPARG, the viral $\mathrm{R}$ proteins of HIV-1 may also inhibit adipocyte maturation and disrupt lipogenesis. ${ }^{84,85}$

Localized lipodystrophy. Localized lipodystrophies are focal losses of subcutaneous fat (Table 2). Various injections, panniculitis and disproportionate direct pressure can cause injury to the subcutaneous adipose tissue inducing dimpling in the overlying skin. ${ }^{86}$

\section{CONCLUSIONS}

The goal of this paper was to evaluate and describe the classification of the more common lipodystrophic syndromes and the underlying mechanisms responsible for the affiliated metabolic abnormalities observed. Major genetic factors in the generalized forms of the lipodystrophies, particularly CGL-Berardinelli-Seip Syndrome are the AGPAT2, BSCL2, CAV1 and PTRF genes. In the acquired forms, genes such as LMNA, PPARG, CIDEC and PLIN1 are implicated in FPLD2, or Dunnigan-Variety; and WRN along with RECQL5 in Werner syndrome. Autoimmune causes are particularly noted in APLBarraquer-Simons syndrome and in AGL-Lawrence syndrome; panniculitis has been shown to have a substantial role in the former as well as in other forms of localized lipodystrophies. Patients with HIV exposed to protease inhibitors, NRTIs or NNRTIs while undergoing HAART have led to the current most-prevalent form of the lipodystrophies: LD-HIV, HALS. 
1 Garg, A. \& Agarwal, A. K. Lipodystrophies: disorders of adipose tissue biology. Biochim. Biophys. Acta Mol. Cell Biol. Lipids 1791, 507-513 (2009).

2 Garg, A. \& Misra, A. Lipodystrophies: rare disorders causing metabolic syndrome. Endocrinol. Metab. Clin. North Am. 33, 305-331 (2004).

3 Mallewa, J. E., Wilkins, E., Vilar, J., Mallewa, M., Doran, D., Back, D. et al. HIVassociated lipodystrophy: a review of underlying mechanisms and therapeutic options. J. Antimicrob. Chemother. 62, 648-660 (2008).

4 Nagy, G. S., Tsiodras, S., Martin, L. D., Avihingsanon, A., Gavrila, A., Hsu, W. C. et al. Human immunodeficiency virus type 1-related lipoatrophy and lipohypertrophy are associated with serum concentrations of leptin. Clin. Infect. Dis. 36, 795-802 (2003).

5 Domingo, P., Estrada, V., López-Aldeguer, J., Villaroya, F. \& Martínez, E. Fat redistribution syndromes associated with HIV-1 infection and combination antiretroviral therapy. AIDS Rev. 14, 112-123 (2012).

6 Kershaw, E. E. \& Flier, J. S. Adipose tissue as an endocrine organ. J. Clin. Endocrinol. Metab. 89, 2548-2556 (2004).

7 Agarwal, A. K. \& Garg, A. Genetic disorders of adipose tissue development, differentiation, and death. Annu. Rev. Genomics Hum. Genet. 7, 175-199 (2006).

8 Abate, N. Adipocyte maturation arrest: a determinant of systemic insulin resistance to glucose disposal. J. Clin. Endocrinol. Metab. 97, 760-763 (2012).

9 Rosen, E. D. \& MacDougald, O. A. Adipocyte differentiation from the inside out. Nat Rev. Mol. Cell Biol. 7, 885-896 (2006).

10 Pei, H., Yao, Y., Yang, Y., Liao, K. \& Wu, J. R. Krüppel-like factor KLF9 regulates PPARg transactivation at the middle stage of adipogenesis. Cell Death Differ. 18, 315327 (2011).

11 Bertrand, A. T., Chikhaoui, K., Ben, Yaou R. \& Bonne, G. [Laminopathies: one gene several diseases]. Biol. Aujourdhui 205, 147-162 (2011).

12 Van Maldergem, L., Magré, J., Khallouf, T. E., Gedde-Dahl, T. Jr, Delépine, M., Trygstad, O. et al. Genotype-phenotype relationships in Berardinelli-Seip congenital lipodystrophy. J. Med. Genet. 39, 722-733 (2002).

13 Agarwal, A. K., Simha, V., Oral, E. A., Moran, S. A., Gorden, P., O'Rahilly, S. et al. Phenotypic and genetic heterogeneity in congenital generalized lipodystrophy. J. Clin. Endocrinol. Metab. 88, 4840-4847 (2003).

14 Pardini, V. C., Victória, I. M., Rocha, S. M., Andrade, D. G., Rocha, A. M., Pieroni, F. B. et al. Leptin levels, beta-cell function, and insulin sensitivity in families with congenital and acquired generalized lipoatropic diabetes. J. Clin. Endocrinol. Metab. 83, 503-508 (1998)

15 Magre, J., Delépine, M., Van Maldergem, L., Robert, J. J., Maassen, J. A., Meier, M. et al. Prevalence of mutations in AGPAT2 among human lipodystrophies. Diabetes 52, 1573-1578 (2003)

16 Garg, A., Wilson, R., Barnes, R., Arioglu, E., Zaidi, Z., Gurakan, F. et al. A gene for congenital generalized lipodystrophy maps to human chromosome 9q34. J. Clin. Endocrinol. Metab. 84, 3390-3394 (1999).

17 Agarwal, A. K., Arioglu, E., De Almeida, S., Akkoc, N., Taylor, S. I., Bowcock, A. M. et al. AGPAT2 is mutated in congenital generalized lipodystrophy linked to chromosome 9q34. Nat. Genet. 31, 21-23 (2002).

18 Subauste, A. R., Das, A. K., Li, X., Elliott, B. G., Evans, C., El Azzouny, M. et al. Alterations in lipid signaling underlie lipodystrophy secondary to AGPAT2 mutations. Diabetes 61, 2922-2931 (2012).

19 Agarwal, A. K. \& Garg, A. Congenital generalized lipodystrophy: significance of triglyceride biosynthetic pathways. Trends Endocrinol. Metab. 14, 214-221 (2003).

20 Simha, V. \& Garg, A. Phenotypic heterogeneity in body fat distribution in patients with congenital generalized lipodystrophy caused by mutations in the AGPAT2 or seipin genes. J. Clin. Endocrinol. Metab. 88, 5433-5437 (2003).

21 Cartwright, B. R. \& Goodman, J. M. Seipin: from human disease to molecular mechanism. J. Lipid Res. 53, 1042-1055 (2012).

22 Payne, V. A., Grimsey, N., Tuthill, A., Virtue, S., Gray, S. L., Dalla Nora, E. et al. The human lipodystrophy gene BSCL2/seipin may be essential for normal adipocyte differentiation. Diabetes 57, 2055-2060 (2008).

23 Yang, W., Thein, S., Guo, X., Xu, F., Venkatesh, B., Sugii, S. et al. Seipin differentially regulates lipogenesis and adipogenesis through a conserved core sequence and an evolutionarily acquired C-terminus. Biochem. J. 452, 37-44 (2013).

24 Kim, C. A., Delépine, M., Boutet, E., El Mourabit, H., Le Lay, S., Meier, M. et al. Association of a homozygous nonsense caveolin-1 mutation with Berardinelli-Seip congenital lipodystrophy. J. Clin. Endocrinol. Metab. 93, 1129-1134 (2008).

25 Hayashi, Y. K., Matsuda, C., Ogawa, M., Goto, K., Tominaga, K., Mitsuhashi, S. et al. Human PTRF mutations cause secondary deficiency of caveolins resulting in muscular dystrophy with generalized lipodystrophy. J. Clin. Invest. 119, 2623-2633 (2009).

26 Mercier, I., Jasmin, J. F., Pavlides, S., Minetti, C., Flomenberg, N., Pestell, R. G. et al Clinical and translational implications of the caveolin gene family: lessons from mouse models and human genetic disorders. Lab. Invest. 89, 614-623 (2009).

27 Shastry, S., Delgado, M. R., Dirik, E., Turkmen, M., Agarwal, A. K. \& Garg, A. Congenital generalized lipodystrophy, type 4 (CGL4) associated with myopathy due to novel PTRF mutations. Am. J. Med. Genet. A. 152A, 2245-2253 (2010).

28 Rajab, A., Straub, V., McCann, L. J., Seelow, D., Varon, R., Barresi, R. et al. Fatal cardiac arrhythmia and long-QT syndrome in a new form of congenital generalized lipodystrophy with muscle rippling (CGL4) due to PTRF-CAVIN mutations. PLoS Genet. 6, e1000874 (2010)

29 Garg, A. Clinical review: Lipodystrophies: genetic and acquired body fat disorders. J. Clin. Endocrinol. Metab. 96, 3313-3325 (2011).

30 Pope, E., Janson, A., Khambalia, A. \& Feldman, B. Childhood acquired lipodystrophy: a retrospective study. J. Am. Acad. Dermatol. 55, 947-950 (2006).
31 Misra, A. \& Garg, A. Clinical features and metabolic derangements in acquired generalized lipodystrophy: case reports and review of the literature. Medicine (Baltimore) 82, 129-146 (2003).

32 Savage, D. B., Semple, R. K., Clatworthy, M. R., Lyons, P. A., Morgan, B. P., Cochran, E. K. et al. Complement abnormalities in acquired lipodystrophy revisited. J. Clin. Endocrinol. Metab. 94, 10-16 (2009).

33 Misra, A., Peethambaram, A. \& Garg, A. Clinical features and metabolic and autoimmune derangements in acquired partial lipodystrophy: report of 35 cases and review of the literature. Medicine (Baltimore) 83, 18-34 (2004).

34 Fiorenza, C. G., Chou, S. H. \& Mantzoros, C. S. Lipodystrophy: pathophysiology and advances in treatment. Nat. Rev. Endocrinol. 7, 137-150 (2011).

35 Mathieson, P. W., Würzner, R., Oliveria, D. B., Lachmann, P. J. \& Peters, D. K. Complement-mediated adipocyte lysis by nephritic factor sera. J. Exp. Med. 177 1827-1831 (1993)

36 Oswiecimska, J., Ziora, K., Geisler, G. \& Dyduch, A. Acquired partial lipodystrophy in an 11-year-old girl. Pediatr. Int. 50, 714-716 (2008).

37 Hegele, R. A., Cao, H., Liu, D. M., Costain, G. A., Charlton-Menys, V., Rodger, N. W. et al. Sequencing of the reannotated LMNB2 gene reveals novel mutations in patients with acquired partial lipodystrophy. Am. J. Hum. Genet. 79, 383-389 (2006).

38 Garg, A. Acquired and inherited lipodystrophies. N. Engl. J. Med. 350, 1220-1234 (2004).

39 Dunnigan, M. G., Cochrane, M. A., Kelly, A. \& Scott, J. W. Familial lipoatrophic diabetes with dominant transmission. A new syndrome. Q. J. Med. 43, 33-48 (1974).

40 Kobberling, J. \& Dunnigan, M. G. Familial partial lipodystrophy: two types of an $X$ linked dominant syndrome, lethal in the hemizygous state. J. Med. Genet. 23, 120-127 (1986)

41 Garg, A., Peshock, R. M. \& Fleckenstein, J. L. Adipose tissue distribution pattern in patients with familial partial lipodystrophy (Dunnigan variety). J. Clin. Endocrinol. Metab. 84, 170-174 (1999).

42 Garg, A. Gender differences in the prevalence of metabolic complications in familia partial lipodystrophy (Dunnigan variety). J. Clin. Endocrinol. Metab. 85, 1776-1782 (2000).

43 Vantyghem, M. C., Vincent-Desplanques, D., Defrance-Faivre, F., Capeau, J., Fermon, C., Valat, A. S. et al. Fertility and obstetrical complications in women with LMNArelated familial partial lipodystrophy. J. Clin. Endocrinol. Metab. 93, 2223-2229 (2008).

44 Garg, A., Speckman, R. A. \& Bowcock, A. M. Multisystem dystrophy syndrome due to novel missense mutations in the amino-terminal head and alpha-helical rod domains of the lamin A/C gene. Am. J. Med. 112, 549-555 (2002).

45 Subramanyam, L., Simha, V. \& Garg, A. (2010)Overlapping syndrome with familial partial lipodystrophy, Dunnigan variety and cardiomyopathy due to amino-terminal heterozygous missense lamin A/C mutations. Clin. Genet. 78, 66-73.

46 Peters, J. M., Barnes, R., Bennett, L., Gitomer, W. M., Bowcock, A. M. \& Garg, A Localization of the gene for familial partial lipodystrophy (Dunnigan variety) to chromosome 1q21-22. Nat. Genet. 18, 292-295 (1998).

47 Cao, H. \& Hegele, R. A. Nuclear lamin A/C R482Q mutation in canadian kindreds with Dunnigan-type familial partial lipodystrophy. Hum. Mol. Genet. 9, 109-112 (2000)

48 Agarwal, A. K. \& Garg, A. A novel heterozygous mutation in peroxisome proliferatoractivated receptor-gamma gene in a patient with familial partial lipodystrophy. J. Clin. Endocrinol. Metab. 87, 408-411 (2002).

49 Boguslavsky, R. L., Stewart, C. L. \& Worman, H. J. Nuclear lamin A inhibits adipocyte differentiation: implications for Dunnigan-type familial partial lipodystrophy. Hum. Mol. Genet. 15, 653-663 (2006).

50 Caron, M., Auclair, M., Donadille, B., Béréziat, V., Guerci, B., Laville, M. et al. Human lipodystrophies linked to mutations in A-type lamins and to HIV protease inhibitor therapy are both associated with prelamin A accumulation, oxidative stress and premature cellular senescence. Cell Death Differ. 14, 1759-1767 (2007).

51 George, S., Rochford, J. J., Wolfrum, C., Gray, S. L., Schinner, S., Wilson, J. C. et al. A family with severe insulin resistance and diabetes due to a mutation in AKT2. Science 304, 1325-1328 (2004).

52 Rubio-Cabezas, O., Puri, V., Murano, I., Saudek, V., Semple, R. K., Dash, S. et al. LD Screening Consortium. Partial lipodystrophy and insulin resistant diabetes in a patient with a homozygous nonsense mutation in CIDEC. EMBO Mol. Med. 1, 280287 (2009).

53 Gandotra, S., Le Dour, C., Bottomley, W., Cervera, P., Giral, P., Reznik, Y. et al. Perilipin deficiency and autosomal dominant partial lipodystrophy. N. Engl. J. Med. 364, 740748 (2011).

54 Olofsson, S. O., Boström, P., Andersson, L., Rutberg, M., Levin, M., Perman, J. et al. Triglyceride containing lipid droplets and lipid droplet-associated proteins. Curr. Opin. Lipidol. 19, 441-447 (2008).

55 Hegele, R. A., Cao, H., Frankowski, C., Mathews, S. T. \& Leff, T. PPARG F388L, a transactivation-deficient mutant, in familial partial lipodystrophy. Diabetes 51,3586 3590 (2002).

56 Semple, R. K., Chatterjee, V. K. \& O'Rahilly, S. PPAR gamma and human metabolic disease. J. Clin. Invest. 116, 581-589 (2006)

57 Pichierri, P., Ammazzalorso, F., Bignami, M. \& Franchitto, A. The Werner syndrome protein: linking the replication checkpoint response to genome stability. Aging (Albany NY) 3, 311-318 (2011).

58 Doh, Y. J., Kim, H. K., Jung, E. D., Choi, S. H., Kim, J. G., Kim, B. W. et al. Novel LMNA gene mutation in a patient with Atypical Werner's Syndrome. Korean J. Intern. Med. 24, 68-72 (2009). 
59 Chun, S. G., Shaeffer, D. S. \& Bryant-Greenwood, P. K. The Werner's Syndrome RecQ helicase/exonuclease at the nexus of cancer and aging. Hawaii Med. J. 70, 52-55 (2011).

60 Popuri, V., Huang, J., Ramamoorthy, M., Tadokoro, T., Croteau, D. L. \& Bohr, V. A. RECQL5 plays co-operative and complementary roles with WRN syndrome helicase. Nucleic Acids Res. 41, 881-899 (2013).

61 Chen, D., Misra, A. \& Garg, A. Clinical review 153: lipodystrophy in human immunodeficiency virus-infected patients. J. Clin. Endocrinol. Metab. 87, 48454856 (2002).

62 Shlay, J. C., Sharma, S., Peng, G., Gibert, C. L. \& Grunfeld, C. Terry Beirn Community Programs for Clinical Research on AIDS (CPCRA); International Network for Strategic Initiatives in Global HIV Trials (INSIGHT). The effect of individual antiretroviral drugs on body composition in HIV-infected persons initiating highly active antiretroviral therapy. J. Acquir. Immune. Defic. Syndr. 51, 298-304 (2009).

63 Blumer, R. M., van Vonderen, M. G., Sutinen, J., Hassink, E., Ackermans, M., van Agtmael, M. A. et al. Zidovudine/lamivudine contributes to insulin resistance within 3 months of starting combination antiretroviral therapy. AIDS 22, 227-236 (2008).

64 Pacenti, M., Barzon, L., Favaretto, F., Fincati, K., Romano, S., Milan, G. et al. Microarray analysis during adipogenesis identifies new genes altered by antiretroviral drugs. AIDS 20, 1691-1705 (2006).

65 Lagathu, C., Eustace, B., Prot, M., Frantz, D., Gu, Y., Bastard, J. P. et al. Some HIV antiretrovirals increase oxidative stress and alter chemokine, cytokine or adiponectin production in human adipocytes and macrophages. Antivir. Ther. 12, 489-500 (2007).

66 Bastard, J. P., Caron, M., Vidal, H., Jan, V., Auclair, M., Vigouroux, C. et al. Association between altered expression of adipogenic factor SREBP1 in lipoatrophic adipose tissue from HIV-1-infected patients and abnormal adipocyte differentiation and insulin resistance. Lancet 359, 1026-1031 (2002).

67 Murata, H., Hruz, P. W. \& Mueckler, M. The mechanism of insulin resistance caused by HIV protease inhibitor therapy. J. Biol. Chem. 275, 20251-20254 (2000).

68 Sievers, M., Walker, U. A., Sevastianova, K., Setzer, B., Wågsäter, D., Eriksson, P. et al. Gene expression and immunohistochemistry in adipose tissue of HIV type 1-infected patients with nucleoside analogue reverse-transcriptase inhibitor-associated lipoatrophy. J. Infect. Dis. 200, 252-262 (2009).

69 Johnson, J. A., Albu, J. B., Engelson, E. S., Fried, S. K., Inada, Y., Ionescu, G. et al. Increased systemic and adipose tissue cytokines in patients with HIV-associated lipodystrophy. Am. J. Physiol. Endocrinol. Metab. 286, E261-E271 (2004).

70 Hudon, S. E., Coffinier, C., Michaelis, S., Fong, L. G., Young, S. G. \& Hrycyna, C. A. HIV-protease inhibitors block the enzymatic activity of purified Ste24p. Biochem. Biophys. Res. Commun 374, 365-368 (2008).

71 Gibellini, L., De Biasi, S., Pinti, M., Nasi, M., Riccio, M., Carnevale, G. et al. The protease inhibitor atazanavir triggers autophagy and mitophagy in human preadipocytes. AIDS 26, 2017-2026 (2012).

72 Zha, B. S., Wan, X., Zhang, X., Zha, W., Zhou, J., Wabitsch, M. et al. HIV protease inhibitors disrupt lipid metabolism by activating endoplasmic reticulum stress and inhibiting autophagy activity in adipocytes. PLoS One 8, e59514 (2013).
73 Carr, A., Miller, J., Law, M. \& Cooper, D. A. A syndrome of lipoatrophy, lactic acidaemia and liver dysfunction associated with HIV nucleoside analogue therapy: contribution to protease inhibitor-related lipodystrophy syndrome. AIDS 14, F25-F32 (2000).

74 Lee, H., Hanes, J. \& Johnson, K. A. Toxicity of nucleoside analogs used to treat AIDS and the selectivity of the mitochondrial DNA polymerase. Biochemistry 42, 14711-14719 (2003).

75 Divi, R. L., Haverkos, K. J., Humsi, J. A., Shockley, M. E., Thamire, C., Nagashima, K. et al. Morphological and molecular course of mitochondrial pathology in cultured human cells exposed long-term to Zidovudine. Environ. Mol. Mutagen. 48, 179-189 (2007).

76 Maagaard, A. \& Kvale, D. Long term adverse effects related to nucleoside reverse transcriptase inhibitors: clinical impact of mitochondrial toxicity. Scand. J. Infect. Dis. 41, 808-817 (2009).

77 Haubrich, R. H., Riddler, S. A., DiRienzo, A. G., Komarow, L., Powderly, W. G., Klingman, K. et al. AIDS Clinical Trials Group (ACTG) A5142 Study Team. Metabolic outcomes in a randomized trial of nucleoside, nonnucleoside and protease inhibitorsparing regimens for initial HIV treatment. AIDS 23, 1109-1118 (2009).

78 El Hadri, K., Glorian, M., Monsempes, C., Dieudonné, M. N., Pecquery, R., Giudicelli, Y. et al. In vitro suppression of the lipogenic pathway by the nonnucleoside reverse transcriptase inhibitor efavirenz in 3 T3 and human preadipocytes or adipocytes. J. Biol. Chem. 279, 15130-15141 (2004).

79 Blas-Garcia, A., Apostolova, N., Ballesteros, D., Monleón, D., Morales, J. M., Rocha, M. et al. Inhibition of mitochondrial function by efavirenz increases lipid content in hepatic cells. Hepatology 52, 115-125 (2010).

80 Ranade, K., Geese, W. J., Noor, M., Flint, O., Tebas, P., Mulligan, K. et al. Genetic analysis implicates resistin in HIV lipodystrophy. AIDS 22, 1561-1568 (2008).

81 Ryden, M. \& Arner, P. Tumour necrosis factor-alpha in human adipose tissue-from signaling mechanisms to clinical implications. J. Intern. Med. 262, 431-438 (2007).

82 Sevastianova, K., Sutinen, J., Kannisto, K., Hamsten, A., Ristola, M. \& Yki-Järvinen, H. Adipose tissue inflammation and liver fat in patients with highly active antiretroviral therapy-associated lipodystrophy. Am. J. Physiol. Endocrinol. Metab. 295, E85-E91 (2008).

83 Hadigan, C., Borgonha, S., Rabe, J., Young, V. \& Grinspoon, S. Increased rates of lipolysis among human immunodeficiency virus-infected men receiving highly active antiretroviral therapy. Metabolism 51, 1143-1147 (2002).

84 Villarroya, F., Domingo, P. \& Giralt, M. Drug-induced lipotoxicity: lipodystrophy associated with HIV-1 infection and antiretroviral treatment. Biochim. Biophys. Acta 1801, 392-399 (2010).

85 Shrivastav, S., Kino, T., Cunningham, T., Ichijo, T., Schubert, U., Heinklein, P. et al. Human immunodeficiency virus (HIV)-1 viral protein $\mathrm{R}$ suppresses transcriptional activity of peroxisome proliferator-activated receptor \{gamma\} and inhibits adipocyte differentiation: implications for HIV-associated lipodystrophy. Mol. Endocrinol. 22, 234-247 (2008).

86 Garg, A. Lipodystrophies. Am. J. Med. 108, 143-152 (2000). 